\title{
A Moderate Pluralist Approach to Public Health Policy and Ethics
}

\author{
Michael J. Selgelid*, The Australian National University \\ *Corresponding author: Centre for Applied Philosophy and Public Ethics (CAPPE), The Australian National University, LPO Box 8260, ANU, Canberra ACT \\ 2601, Australia. Email: michael.selgelid@anu.edu.au. Home page: http://www.cappe.edu.au/staff/michael-selgelid.htm
}

This article advocates the development of a moderate pluralist theory of political philosophy that recognizes that utility, liberty and equality are legitimate, independent social values and that none should have absolute priority over the others. Inter alia, such a theory would provide a principled means for striking a balance, or making tradeoffs, between these values in cases of conflict. Recent developments in public health ethics have made progress in thinking about how to make trade-offs between liberty and utility in particular. While public health ethicists often claim that the least restrictive alternative should be used to achieve the public health goal in question, I argue that a plausible but under-recognized idea is that the least restrictive alternative might sometimes involve improvement of global health via redistributive taxation-i.e., rather than coercive social distancing measures. I conclude by demonstrating that the proportionality principle leaves open the question of when exactly utility outweighs liberty or vice versa-and I argue that, rather than speaking about the morality of liberty-infringing public health interventions in categorical/binary terms, it would be more fruitful and realistic to think and speak about the degree to which a liberty-infringing public health intervention is morally appropriate.

\section{Introduction}

This article advocates the development of a moderate pluralist theory of political philosophy that recognizes that utility, liberty and equality are legitimate, independent social values and that none should have absolute priority over the others. Inter alia, such a theory would provide a principled means for striking a balance, or making trade-offs, between these values in cases of conflict. Recent developments in public health ethics have made progress in thinking about how to make trade-offs between liberty and utility in particular. While public health ethicists often claim that the least restrictive alternative should be used to achieve the public health goal in question, I argue that a plausible but underrecognized idea is that the least restrictive alternative might sometimes involve improvement of global health via redistributive taxation-i.e., rather than coercive social distancing measures. I conclude by demonstrating that the proportionality principle leaves open the question of when exactly utility outweighs liberty or vice versa - and I argue that, rather than speaking about the morality of liberty-infringing public health interventions in categorical/binary terms, it would be more fruitful and realistic to think and speak about the degree to which a liberty-infringing public health intervention is morally appropriate.

\section{Against Applying Theory to Context}

'Applied Ethics', and thus presumably 'public health ethics', means different things to different people. For many, applied ethics involves applying an existing ethical theory to a particular concrete context of interest: one simply cranks out her favorite theory in the context under consideration. In the context of public health, then, one might choose from among the most popular mainstream theories of political philosophy-say, utilitarianism, libertarianism or (Rawlsian) egalitarianism-and explore its implications for public health policy making. In some cases these theories may yield different answers, but this is not inevitable. When all three yield the same answer, it might be sufficiently clear what should be done. In cases like this we have convergence, or an 'overlapping consensus' (Rawls, 1993), between major political philosophy perspectives. When diverse plausible or semi-plausible theories all point in the same direction, then that is at least telling.

Things are not so easy, however, when these theories yield answers that conflict with one another. Conflict between different theories' answers to specific questions often reflects conflict between the values these theories emphasize. Utility, equality and liberty sometimes travel together, but this is not always the case. In cases where such values conflict we apparently must choose between 
them or, one might think, the theories that emphasize them to different degrees.

Conflicting values are commonplace in the context of public health, and the context of infectious disease in particular. In the case of epidemic diseases, for example, the measures required for the protection of public health may include surveillance; mandatory vaccination, testing or treatment; and/or social distancing measures such as isolation and quarantine. Though measures like these may sometimes promote the greater good of society in the way of public health or utility (i.e., aggregate wellbeing), they each conflict with widely acknowledged basic human rights and liberties. Surveillance conflicts with (the right to) privacy; mandatory vaccination, testing and treatment conflict with (the right to) informed consent to medical intervention; and coercive social distancing measures conflict with (the right to) freedom of movement (Selgelid, 2005).

Imagine a context where there is every reason to believe that coercive isolation and quarantine would promote public health and utility overall (i.e., over the long run, all things considered). Utilitarianism would call for infringing freedom of movement in such a scenario; and libertarianism would presumably hold that public health/utility must be compromised in the name of the individual's (right to) freedom of movement.

The answers of utilitarianism and libertarianism, however-in my opinion anyway-are really not all that interesting or important. If neither of these theories is correct-or in line with ordinary, widespread, unshakeable visions of morality-then who cares what they say we should do? The problem with utilitarianism and libertarianism is that they each place extreme, and arguably implausible, weight on the values they emphasize. Utilitarianism holds that utility takes absolute priority - and that liberties must be compromised whenever liberty restriction is required to maximally promote utility overall (i.e., over the long run, all things considered). Libertarianism, on the other hand, calls for the opposite: (negative) liberty takes priority and must not be infringed for the sake of utility promotion.

Most individuals and policy makers, however, would reject both of these views. Most of us deny that human rights to liberty should be violated whenever this would lead to a net payoff in terms of utility, because we think that human rights/liberties matter too (Dworkin, 1978). We do not, thus, think that the aim to promote utility is overriding. Utility obviously matters, but we think it is at least sometimes outweighed by liberty and/or equality.

\section{Utility Outweighed}

\section{Utility outweighed by liberty}

Suppose that utility could in fact be promoted via involuntary organ donation. Imagine that we could capture an individual, harvest her organs (killing the involuntary donor in the process) and use them to save five other lives. And imagine, hypothetically, that we could somehow successfully manage side effects so that we really could thus bring about a net gain in utility overall. I would guess that almost everyone agrees that involuntary organ donation-e.g., by healthy, innocent, unwilling individuals—-would be wrong even if, hypothetically, we could be confident it would promote utility overall. It would be insufficient for a defender of utilitarianism to deny that utility could be promoted by involuntary organ donation by arguing that the imagined circumstances could never in fact arise, e.g., because side effects could not be managed as stipulated, and so on. The point of this example is to demonstrate that if it were hypothetically possible to maximize utility in the way imagined, then this is what utilitarianism would say we should do. The intuition that involuntary organ donation would be wrong, even if it were in fact utility maximizing, reflects the idea that human rights and liberties can, in principle, sometimes outweigh utility.

In the context of public health, the idea that utility is sometimes outweighed by liberty is reflected by the wide appeal of the proportionality principle (which will be further discussed later in this article), according to which a liberty-violating public health measure would only be justified when the utility costs of refraining from coercion would be high. According to this principle, coercive isolation and quarantine may sometimes be justified when necessary to prevent a major utility loss; but such coercive measures would not be considered appropriate on any/every occasion where their use would lead to a maximization of utility (i.e., when the utility gain would be small).

\section{Utility outweighed by equality}

For a second example, imagine that one group of innocent people live miserable lives due to brute bad luck and that a second group of especially undeserving individuals live tremendously wonderful lives. Imagine that we had the choice of either (public health) Policy A, which would improve the innocent miserable lives by one billion units of utility overall, with no net effect on the undeservingly well-off group; and (public health) Policy B, which would improve the undeservingly well-off individuals' lives by one billion and one units of utility, with no net effect 
on the innocent miserable group. Utilitarianism would call for adoption of Policy B, but I would assume that almost everyone believes that Policy A-which would go a long way toward promoting equality (i.e., reducing undeserved inequalities in well-being) while promoting nearly as much utility at the same time-is ethically superior, by far, other things being equal. If this assumption is correct, then this goes to show that most of us think that utility is at least sometimes outweighed by equality and, in the case of the example, that the huge gain in equality matters more than a tiny gain in utility.

While different utilitarian theories conceptualize 'utility' - i.e., a measure of well-being — in different ways, the counter-examples above are meant to apply to utilitarian theories in general. The examples have force whether aggregate utility is thought to consist in an aggregation of happiness/pleasure, desire/preference satisfaction or according an 'objective list' of components of well-being. My own view is that utility/well-being should itself be conceived pluralistically—as argued by Griffin (1986), Brock (1993), and Kitcher (1996). The purpose of the examples is to show that the goal to maximally promote well-being, however conceived, is sometimes outweighed by goals to promote liberty and/or equality. ${ }^{1}$

\section{Liberty Outweighed}

\section{Liberty outweighed by utility}

Most would presumably likewise agree that negative rights and/or liberties ${ }^{2}$ should not have absolute priority either. When the threat to utility is great enough, most would agree that negative rights and liberties must be sacrificed. In just wars, for example, we find it necessary to violate innocent people's right to life-i.e., the most basic right of all. If the consequences of failing to impose isolation or quarantine on a single individual infected with a highly deadly and contagious mutant strain of disease would be apocalyptic — predictably causing millions (or billions) of preventable deaths-then most would presumably agree that the liberty infringement would be justified. In this and the case of war, the intuition is that negative rights/liberties must be sacrificed when the utility stakes are high enough. Even Nozick (in a footnote) hints that liberty/rights violations may be justified when necessary to prevent 'catastrophic moral horror' (Nozick, 1974, 30n).

\section{Liberty outweighed by equality}

Though Nozick denies that (negative) liberty violations would be justified in order to promote social equality-e.g., by improving the situation of the worstoff groups of society-this is widely considered to be an Achilles heel of his theory. Those who, on egalitarian grounds, accept redistributive taxation policies found in virtually every Western democracy are committed to the idea that (negative) liberty is at least sometimes outweighed by equality.

\section{Equality Outweighed}

\section{Equality outweighed by utility}

Similar things can be said about equality. A central idea of Rawls (1971) is that policy should aim to maximally improve the situation of the worst-off groups of society. Though most would probably agree that improving the situation of the worst-off groups of society is a laudable/legitimate egalitarian goal, we do not think that this is the only thing that matters or that it must be achieved at any cost. If slightly improving the situation of the worst-off groups of society would entail enormous costs in terms of utility, for example (which Rawls empirically denies would be the case), we would deny that equality (qua maximin) reigns supreme.

Imagine anencephalic babies born without brains. They are arguably among the worst-off groups/members of society. Though their situation is about as dire as it gets, it is at least theoretically possible that their situation could be improved if health resources (including public health and research resources) were more thoroughly focused on them. We might, that is, find a way to at least slightly boost their brain capacity, functioning and wellbeing if we only put enough effort into it. Imagine that the more health resources we focused on them, the better off they would be. And imagine, given that their situation is so hopeless to begin with, that the total improvement in their well-being could be only slight no matter how many health resources we devote to them. A radical diversion of health resources could imaginably make anencephalic children-i.e., the worst off-better off; but this would have tremendous utility costs assuming that other areas of public health and medicine (from which resources would be diverted) are much more fruitful in the promotion of human well-being (Selgelid, 2002). The idea here is that we are better able to convert health resources into well-being in other (more ordinary) areas of public health and medicine- and that this, as well as the fact that there are so few anencephalic babies to begin with, is why health/research resources should usually focus on other things. If a minor improvement in the situation of anencephalic children entailed enormous costs in terms of health for everyone else (i.e., those who are better off), 
then most would presumably deny that the diversion of health resources in question would be appropriate.

To pre-empt the objection that babies born without brains do not count as persons-and that Rawls' theory is thus not meant to apply to them-it should be noted that a similar argument applies to any (real or imaginary) case of (indisputable) persons with a health condition that is (i) so bad that it places them among the worst-off groups of society and (ii) so hopeless that, even if we focused enormous amounts of health (including research) resources on it, only a slight improvement would be possible. Nothing turns on the idea that anencephalic children are persons.

The above argument insinuates that application of Rawls' theory of justice to the context of healthcare would ultimately call for making the worst off as well off as possible in terms of well-being. Norman Daniels, however, argues that Rawlsian distribution of health resources would aim at equality of opportunity rather than necessarily maximizing the well-being of those who are worst off (Daniels, 1985). Even if equality of opportunity should be the aim of Rawlsian egalitarianism in the context of healthcare, however, the same kind of counterexample can be put forward. Focusing health resources on increasing the opportunities of anencephalic children, or others with similarly hopeless conditions, would likewise entail an enormous utility cost in order to achieve what could presumably only be a tiny gain in equality of opportunity.

The problem with Rawls is that the idea that we should maximally improve the situation and/or increase the opportunities of those who are worst off and/or have the fewest opportunities appears implausibly extreme when we imagine cases where the utility costs of achieving even small gains for such groups would be enormous. Almost everyone would agree that equality is outweighed by utility when the utility stakes are high enough.

\section{Equality outweighed by liberty}

Equality is arguably also sometimes outweighed by liberty. Though Nozick may not succeed in showing that liberty always outweighs equality, we should admit that his examples and arguments at least support this weaker claim. Nozick convincingly shows that thinking otherwise would commit us to an enormously intrusive form of government. This is the real strength of Anarchy, State and Utopia — and the reason why his arguments, and especially the example involving basketball, seem at least somewhat compelling. We can reject his theory but at least give him credit for this. A less theoretical illustration of the idea that equality is at least sometimes out- weighed by liberty is reflected by the common intuition that communism would be wrong even if it worked better in practice-i.e., because the equality it would achieve would come at too high a cost in terms of liberty if people would not even be free to choose their careers and so on.

Though much of my discussion of equality (being outweighed) has focused on Rawls (in virtue of the enormous popularity and influence of his theory), it should be noted that similar counter-examples might (be generated to) address alternative popular egalitarian theories. There is much debate about whether the egalitarian goal should aim at equality of resources, equality of welfare, or equality of opportunity (which is common to numerous egalitarian positions, including 'luck egalitarianism' and Sen's (1992) view regarding equality of capabilities (Daniels, 2007)). There may be good reason to think that the egalitarian goal should itself be pluralistic: i.e., that we should, other things being equal, aim at equality in each of these dimensions (striking a balance between them in cases of conflict) rather than choosing between them. ${ }^{3}$ When the egalitarian aim is conceived in any of these ways, however, we can presumably ${ }^{4}$ imagine cases (similar to those described above) where the utility and/or liberty costs of achieving that aim would be enormous - and, if that is correct, then the question of why equality should always trump these other social values (which sounds implausibly extreme) arises. The argument three paragraphs above regarding equality of opportunity is especially telling, because equality of opportunity is common/central to numerous prominent egalitarian theories, as is demonstrated by Daniels (2007). If there are plausible egalitarian aims whose promotion would never (even hypothetically) lead to enormous utility and/or liberty costs, on the other hand, then the question of such aims having absolute priority over utility and/or liberty, or claims that they (should) have such priority, need never arise. If there could be no significant conflict, the question of which value has absolute priority does not apply. ${ }^{5}$

\section{Moderate Pluralism $^{6}$}

Common-sense reactions to the cases considered above reveal that most of us think that utility, liberty and equality are each independently valuable and that none should have absolute priority over the others. A straightforward explanation for the long-standing debates between utilitarianism, libertarianism and Rawlsian egalitarianism is that each of these theories is partly right (vis-à-vis common-sense morality), because the values these theories emphasize-i.e., utility, liberty and equality, respectively_each really matter. But the debates 
between them, and the numerous counter-examples provided therein, show that each is also wrong (vis-à-vis common-sense morality) because they each place implausibly extreme weight on the values they emphasize. Why chose between these theories if none of them captures what we really think about morality/ethics?

The elephant in the room too rarely mentioned is that most of us are, upon reflection, committed to the idea that utility, liberty and equality are each legitimate social goals and that none should have absolute priority over the others. ${ }^{7}$ What we really need, then, is a fourth-more moderate and pluralistic-framework of political philosophy that provides a principled way for striking a balance between them in cases of conflict. Though others-such as Amartya Sen (1999), Buchanan et al. (2001) and Daniels (2007) — have made similar points, no well-developed theory for striking such a balance appears to be on offer in mainstream political philosophy or bioethics. That no such theory is in common currency in bioethics is, in any case, partly revealed by introductory chapters to standard textbooks in bioethics-which run through the main theoretical approaches to ethics, but usually say relatively little if anything about how to deal with conflict between multiple, legitimate social values. ${ }^{8}$ Until such a theory is developed, the approach of applied ethics I mentioned at the beginning of this article-i.e., the application of existing theories to concrete cases-should not be considered all that promising, if, as I surmise, a large proportion of ethical questions arise because of conflicting values. When and if a convincing theory along these lines is developed in detail, on the other hand, such an approach might be apt.

Before going on, I must make some caveats. Above I merely asserted that most would react to the cases presented in the ways I suggested. Though I am confident that this is correct, I cannot offer empirical evidence at this time. I would advocate that relevant empirical research gets done. Even if most people do think something, however, this does not mean they are right to think so. A claim to the contrary would fall victim to the wellknown fallacy of 'appeal to the people'. If most people would react to the cases in the way I suppose, this would not show that utilitarianism, libertarianism and Rawlsian egalitarianism (or the ideas that one of the three values - utility, liberty, equality—should have absolute priority over the others) are wrong. It would merely show that they are incompatible with common-sense morality and/or widely shared moral intuitions. I am happy to admit that each of these three theories (or ideas) is possibly correct - and that none of them can be disproved by philosophy, logic or science. The problem, however, if I am right about what are widely shared intuitions about the cases presented, is that none of these theories (or ideas) capture the more moderate and pluralistic moral perspectives of ordinary people and policy makers. Just as utilitarianism, libertarianism and Rawlsian egalitarianism cannot be disproved by philosophy, logic and/or science, the same can presumably be said about at least some theories that strike more balance between utility, liberty and equality. All four theoretical perspectives might be compatible with philosophy, logic and science, but the fourth (if well developed) could have the added advantage of being in line with ordinary moral thinking and widely accepted policy making. For the most part, only philosophers (and dare I say fundamentalists) subscribe to utilitarianism, libertarianism or Rawlsian egalitarianism (or the ideas that one of the three values-utility, liberty, equality—should have absolute priority over the others). A quick look at ordinary behavior and policy making reveals that most of us are more moderate and pluralistic at heart.

\section{Application of Context to Theory Development}

A second approach to applied ethics is more theoretical. In this case we look at concrete cases with the aim to both (1) develop theoretical perspectives and (2) find answers to specific real-world ethical questions. With regard to the former aim, the idea is that consideration of the richness of concrete cases is instrumental for the purpose of theory development.

Let us, then, return to the context of coercive social distancing measures (such as isolation and quarantine) and see where this leads (or where relevant analyses have already led) with respect to development of the fourth theoretical perspective-which I call 'moderate pluralism'. A moderate pluralist approach to public health policy would start with the aim to promote utility, liberty and equality as independent legitimate social goals, and the aim to strike a balance or make trade-offs between them in cases of conflict, without giving absolute priority to any one of these goals in particular (or taking any one of them to be the 'default value'). The question of how to strike a balance or make trade-offs between these goals, or the question of how to weigh these goals against one another, in cases of conflict is especially difficult because of the apparent incommensurabilities involved. To strike such a balance or make such tradeoffs, that is, we would apparently need to know how much utility is worth how much liberty, how much utility is worth how much equality and so on. To think that 
utility sometimes outweighs liberty or equality, that is, we might need to think that-for some quantities $\mathrm{X}, \mathrm{Y}$ and $\mathrm{Z}-\mathrm{X}$ amount of utility is worth $\mathrm{Y}$ amount of liberty and $Z$ amount of equality. Comparing utility, liberty and equality, however, might be like comparing apples, oranges and bananas. This difficulty-and possible ways of dealing with it - will be further illustrated below.

Meanwhile, it is worth pointing out that it may be dubious that there is some simple conversion formula that holds in all contexts and tells us, for example, that a gain of $\mathrm{X}$ amount of utility would be equal to a gain of $\mathrm{Z}$ amount of equality (in promoting the good of society). ${ }^{9}$ In some contexts we might judge that $\mathrm{X}$ amount of utility would contribute more to the good of society than $\mathrm{Z}$ amount of equality; but, in other contexts we might judge that $Z$ amount of equality would contribute more toward the good of society than X amount of utility. ${ }^{10}$ Similar things might be said when we make comparisons between utility and/or equality with liberty.

Perhaps the importance, priority or weight that should be given to the promotion of any one of these goals should not be fixed but, rather, context dependent. The importance of equality, for example, should arguably depend not only on the magnitude or degree of inequality, but should also depend on the nature ${ }^{11}$ of the inequalities in question. It seems plausible that the promotion of equality should be given greater weight-i.e., will contribute more to the good of society-to the degree that:

(1) there are groups of people living the lowest ${ }^{12}$-quality lives

(2) this is preventable

(3) there are larger numbers of people who avoidably live such lives, and/or

(4) worse-off individuals cannot reasonably be considered to be responsible for their plight.

When we can reduce inequalities by substantially elevating the well being of relatively large numbers of innocent people living the lowest-quality lives, then we should arguably be more willing to sacrifice utility and/or liberty (to achieve a certain magnitude of equality) than would otherwise be the case.

The promotion of equality should perhaps be given less weight, on the other hand, to the degree that

(1) the groups in question already live high-quality lives and have their most basic needs met

(2) equality can primarily only be promoted by decreasing the well-being of certain groups (i.e., when inequalities can only be reduced by lowering the wellbeing of the not-so-bad-off rather than substantially elevating the well-being of the worst-off individuals)
(3) there are smaller numbers of persons in the not-sowell-off groups, and/or

(4) the persons who are not-so-well-off are responsible for the fact that they are not-so-well-off.

To the degree that decreases in inequality would require reductions rather than improvements in wellbeing; to the degree that they would be focused on improving the situation of persons who are responsible for their misfortunes; and to the degree that almost everyone is already quite well off and has her most basic needs met, then, we should perhaps be less willing to make sacrifices in aggregate utility and/or liberty than otherwise would be the case.

The importance of liberty and utility might likewise be context dependent. An implication of the above discussion of equality, for example, is that liberty (vis-àvis equality, anyway) matters more in contexts where everyone is (or more people are) relatively well off. Another idea is that liberty matters more in contexts where more basic liberties are at stake-because more basic rights/liberties deserve more protection than others. An implication of the above discussion is likewise that utility maximization (vis-à-vis equality, anyway) matters more in contexts where everyone is (or more people are) relatively well off. Another idea is that the aim to promote utility should be weighted in proportion to the magnitude of utility threatened.

\section{Bypassing Conflict}

As noted above, coercive social distancing measures are paradigmatic examples of issues raising conflicting values. Depending on the disease, there may be cases where coercive isolation and quarantine would promote utility in the way of public health-but such measures would conflict with the widely acknowledged right to freedom of movement. Perhaps the best way to deal with conflicting values is to bypass conflict altogether. The idea that we must choose between liberty and utility in contexts where isolation/quarantine are called for may often be a false dilemma.

At present, the case for isolation and/or quarantine is perhaps especially compelling in the context of 'extreme' or 'extensively' drug resistant tuberculosis (XDRTB) (Singh et al., 2007). These strains of tuberculosis (TB) are so drug resistant that they usually kill 40 per cent of their victims, even when treatment is provided. This is not much different from TB's death rate before effective treatments became available, and XDRTB is thus often considered to be 'virtually untreatable'. A suspected case of XDR-TB in 2007 resulted in the first 
federal isolation/quarantine order in the United States since 1963 (Selgelid, 2008a), and a man in Arizona with XDR-TB has been held in prison-like conditions for over a year. Prison-like confinement of XDR-TB patients is also occurring at present in South Africa.

The existence and extent of XDR-TB, however, is largely a product of poor healthcare in developing countries. Though TB cures have existed since the 1950s, and though ordinary TB medication is inexpensive (costing only $\$ 10-\$ 20$ for a six-month course of therapy, which is curative in the vast majority of cases), TB kills 1.7 million people yearly. Two billion people-i.e., one-third of the world's population-are infected with the latent form of the disease, and 5-10 per cent of these are expected to develop active illness at some time in their lives. There are 15 million active TB cases every year. Ninety-five per cent of cases and 98 per cent of TB deaths occur in developing countries. The poor are especially susceptible and vulnerable to TB because malnutrition weakens their immune systems, making infection and illness more likely. Other factors include overcrowded living and working conditions, poor hygiene and sanitation and lack of education. To make matters worse, the poor often lack access to basic TB medications, despite the fact that they are inexpensive. For these and other reasons, the poor are both more likely to become infected with $\mathrm{TB}$ and more likely to suffer bad outcomes when they do become infected. Similar things can be said about poor people's susceptibility and vulnerability to other infectious diseases.

Drug resistant $\mathrm{TB}$, finally, often occurs when patients start medication but then do not finish it. In developing countries, where the TB burden is by far the highest, the explanation for treatment incompletion is often that patients are unable to complete treatments they have started-because they cannot continue to afford the medications (which they often need to pay for out of pocket) or because they are unable to afford time off work or (often difficult) travel to (often faraway) clinics. Another common problem is that, due to weak healthcare infrastructure in developing countries, drug stockouts are common and thus medicines become unavailable to even those who would have been able to afford them and make their way to the clinic (Farmer, 2001).

The upshot is that the problem of XDR-TB - and thus the apparent need for isolation/quarantine-is largely a function of poverty and the healthcare situation in developing countries. If the healthcare situation in developing countries was not so bad to begin with, then the extent of drug resistance (both with regard to the number of drugs that TB strains are resistant to and with regard to the prevalence of XDR-TB strains in particular) would be less, and the occasions where isolation/quarantine are called for would not arise so frequently. Improvement in basic TB control programs for impoverished populations would promote utility in the way of public health (especially because standard TB medications are usually considered to be among the most cost effective healthcare interventions). Because the poor who suffer from TB are among the worst-off groups of society, improvement in TB control programs would also promote equality. (And the discussion above suggests that equality should receive an especially high weighting in the context of TB.) Improvement in basic TB control programs would thus promote utility, equality and-because the need for isolation and quarantine would arise less often-liberty at the very same time. When relevant empirical information is taken into account, it might seem obvious what ethical public health policy making should call for: improvement of global health via redistributive taxation. ${ }^{13}$

This yields a principle of moderate pluralism with broader application: In cases where there is apparent conflict between utility, liberty and/or equality, we should seek creative ways of promoting all three at the same time. Though this may sound like an obvious principle, we should keep in mind that it is a far cry from the most popular perspectives in mainstream political theory. Utilitarianism, for example, says we should aim to promote utility without paying any attention to liberty and equality except insofar as liberty and equality are instrumental in the promotion of utility, and except insofar as we weight each person's well-being equally when making utility calculations.

Insofar as improvement in the health of the poor would require redistributive taxation, however, the conflict between liberty and equality and/or utility would not go away altogether-because improvement of global health via redistributive taxation itself involves liberty infringement, as is demonstrated by Nozick (1974). Even if TB control programs were strengthened in the future, furthermore, XDR-TB might not disappear completely — and other, perhaps new, highly contagious and deadly infectious diseases may lead to calls for isolation and quarantine. What should be done when conflict between liberty and utility is unavoidable?

\section{Progress-and Remaining Hurdles-for Public Health Ethics}

The good news, regarding development of a moderate pluralist approach to health policy making, is that recent growing discourse in public health ethics has made substantial progress in thinking about how to address 
conflict between utility and liberty in particular. Recognizing that liberty and utility often conflict in public health contexts - and that, as illustrated above, we might sometimes need to compromise liberty for the sake of utility in the way of public health-various authors have proposed frameworks for public health policy making (Kass, 2001; Upshur, 2002; Gostin, 2006; Selgelid, 2009) that point toward a principled way of making trade-offs between the social values in question.

Among other things, it has been argued that (i) liberty restriction in the name of public health protection should be based on evidence that the intervention in question would in fact provide an effective means of public health protection; (ii) the least restrictive (i.e., least liberty-infringing) alternative should be employed to achieve the public health goal in question; (iii) extreme liberty-infringing methods such as isolation and quarantine should not be employed unless the consequences would otherwise be severe; (iv) liberty-infringing interventions should be used in an equitable-i.e., nondiscriminatory-manner and/or the bar for imposing such measures should be highest (with regard to the evidence required or the utility threatened) when those being considered for confinement are members of the worst-off groups of society; (v) liberty-infringement should be minimally burdensome (e.g., so that those who are confined have their basic needs met and are made as comfortable as possible); (vi) those whose liberty is violated should be compensated in return; (vii) implementation of liberty restrictions should involve due (legal) process, and those confined should have a right to appeal; and (viii) relevant policy making should (insofar as possible) be democratic and transparent.

\section{Least restrictive alternative}

Suppose that the consequences of XDR-TB would in fact be severe and that there is good reason to believe that a disease burden from XDR-TB of magnitude B could be avoided via implementation of measures such as isolation and quarantine. If $B$ is sufficiently large, then-according to the third criterion, which is often referred to as the principle of proportionality-isolation and quarantine might be appropriate so long as the other criteria are met. As indicated above, however, the need to employ such measures might be prevented if global health were improved via redistributive taxation, which would likewise itself involve some liberty infringement. Suppose that there was good reason to believe that a disease burden from XDR-TB of magnitude B could be avoided via improvement of global health via redistributive taxation. If, as seems plausible, the increased taxation required for improvement of global health would involve a less restrictive (i.e., less liberty-infringing) interference than coercive isolation and quarantine, then the second criterion would call for improvement of global health via redistributive taxation rather than isolation and quarantine. The under-recognized idea that improving global health via redistributive taxation might sometimes provide the least restrictive means of public health protection thus warrants further consideration.

\section{Proportionality}

Above I suggested that a moderate pluralist theory would provide a principled way of making trade-offs between utility, liberty and equality_ and I suggested that to think that utility sometimes outweighs liberty, or vice-versa, we might need to think that (in any given context)—for some values $\mathrm{X}$ and $\mathrm{Y}-\mathrm{X}$ amount of utility is worth $\mathrm{Y}$ amount of liberty. Returning to this issue we find that the public health framework outlined above does not provide all we need to obtain a principled way for making trade-offs between liberty and utility. The proportionality principle holds that the utility stakes would need to be high for liberty restrictions to be justified, but it does not say how great the utility stakes would need to be in order for a given liberty restriction to be justified. ${ }^{14}$ Imagine that the free movement of a patient with a particular strain of some infectious disease would on average lead to additional disease burden $\mathrm{B}$, perhaps measured in DALYs ${ }^{15}$ in the context of consideration. How great would $\mathrm{B}$ need to be for confinement of an individual for a given period of time to be justified? This is arguably the key philosophical question that arises in the context of isolation and quarantine. Given the apparent incommensurabilities between utility and liberty, however, it is hard to imagine how we might go about answering such a question; and it is perhaps doubtful that there could be a right answer. The latter point is that it is hard to believe that there is some magic number B such that it would be ethically acceptable to confine a person for time $\mathrm{T}$ so long as B or more DALYs would thereby be prevented, but unacceptable so long as less than B DALYs would thereby be prevented.

Rather than thinking that any given liberty-infringing intervention is categorically either acceptable or unacceptable, it may be more fruitful to think in terms of degree: the more DALYs at stake, the more acceptable the liberty infringement would be; and the less DALYs at stake, the less acceptable the liberty infringement would be. We might thus aim to locate any given liberty-restricting public health intervention on a moral spectrum-according to which interventions range from 
the most morally appropriate at one end of the spectrum (where the most DALYs are at stake) to the most morally problematic at the other end of the spectrum (where the least, or no, DALYs are at stake), over a morally neutral territory somewhere in between. We would then talk about the degree to which (given its location on the spectrum) any given liberty restriction was acceptable or not rather than talking about whether it was acceptable or not.

This initially sounds unsatisfying. Because we must take one action or another, we think we need to know which actions would be acceptable and which would be unacceptable; and we want our theory to provide a clear guide to action. A moral spectrum - and talk about degrees of acceptability and unacceptability-does not tell us what should be done if there is no (identifiable) threshold/line in the spectrum dividing the acceptable actions from those that are unacceptable.

In the hardest cases-i.e., where we lack intuitions about whether liberty outweighs utility or vice versa, given the magnitudes of liberty and utility at stake-it may, ironically, matter least which action is actually taken. Imagine the gray area of the moral spectrum where, given the number of DALYs at stake, it is unclear whether or not confinement of an individual for a given period of time would be called for. Suppose that-despite the fact that we do not know what the number is or how to determine what the number is-there really was a fact of the matter regarding how many DALYs would need to be prevented in order for confinement to be justified. Suppose that the actual threshold for confinement to be justified is (exactly) 10 DALYs. If that were so, then speaking in categorical/binary terms, confining an individual for the time period in question would be acceptable so long as this would prevent 10 or more DALYs and unacceptable if this would prevent less than 10 DALYs. Because this kind of categorical/binary speaking does not tell us how good or bad the action in question would be, however, there is a way in which such categorical/binary speaking carries less information than speaking in terms of degrees and spectrums. If 10.000001 DALYs were prevented, confinement would be considered acceptable; and if 9.999999 DALYs were prevented, confinement would be considered unacceptable. In reality, however, the difference in the utility at stake-and thus the ultimate difference in the moral acceptability of liberty restriction in the two cases, other things being equal ${ }^{16}$ — would be negligible. Cases immediately on either side of the hypothetical line/threshold would fall in the morally neutral range of the moral spectrum - and the line itself would appear not to be very necessary/important. Even if there was an actual threshold/line (at 10 DALYs), however, considera- tion of degree is essential. Mere binary thinking is insufficient because it would put confinement in a case where 0 DALYs are at stake (which would be very bad) on a par with confinement in a case where 9.999999 DALYs are at stake (which would be morally neutral) — both would simply be labeled 'unacceptable'-despite the fact that the moral difference between these two cases would be great. Mere binary thinking would put confinement in a case where 10 million DALYs are at stake (which would presumably be highly appropriate) on a par with confinement in a case where 10.000001 DALYs are at stake (which would be morally neutral) — both would simply be labeled 'acceptable' - despite the fact that the moral difference between these two cases would be great. The upshot of this discussion is that binary thinking in this context is neither sufficient nor very necessary/important. ${ }^{17}$ If there are no magic numbers or clear ways to identify threshold lines, furthermore, such thinking is not very realistic.

\section{The way forward}

The way forward, therefore, may not require identification of thresholds where given amounts of utility outweigh given amounts of liberty and/or equality and so on. Even if there are such thresholds, in the morally neutral territory of a spectrum it matters relatively little whether the action taken falls above or below the supposed threshold. The more important task may thus be to roughly identify the area on the moral spectrum-ranging from the most morally problematic at one end to the most morally appropriate at the other, over the morally neutral somewhere in between - where any given public health intervention would fall. In the final analysis, policy makers will inevitably have to make judgments about whether or not and/or the extent to which utility outweighs liberty and/or equality, and so on, in any given case.

\section{Notes}

1. The examples are by no means, however, meant to discredit consequentialism in general. A consequentialist theory with a complex/pluralistic theory of the good could take utility, liberty and equality into account when assessing the 'best' outcome. Utilitarianism, as I understand it, is a consequentialist theory with an impoverished theory of the good, because it only takes aggregation of individual well-being (however conceived) into consideration. A purpose of this article is to argue that we should think pluralistically about the social good (just as we should, as is persuasively argued by Griffin and others, think pluralistically about individual well-being). 
2. An explicit discussion of positive rights and liberties is beyond the scope of this article, but I would argue that if the utility, equality and/or negative rights/liberties costs of achieving them were enormous, it may likewise be dubious to think that the goal to promote positive rights and liberties should (always) take absolute priority over these other legitimate social aims.

3. Just as, I am arguing, we should aim at the promotion of utility, liberty and equality rather than choosing between them.

4. I do not have space in this article to provide so many counterexamples.

5. Asking such a question, according to (my understanding of a personal discussion with) David Armstrong, would be (akin to) a 'category mistake'.

6. The idea of moderate pluralism is not that it is moderate (as opposed to thoroughgoing) in its pluralism. The idea is a pluralism that moderates between a plurality of values without giving absolute (i.e., lexical) priority to any value(s) in particular.

7. I focus on a holy trinity of utility, liberty and equality, because these are the values emphasized by the three main strands of political theory (utilitarianism, libertarianism and egalitarianism) - and because they are especially important (and a focus of discussion) in public health ethics. I do not mean to suggest, however, that this is necessarily an exhaustive list of legitimate independent social values. Additional possibilities include solidarity and other communitarian values (though solidarity and community may ultimately be about pursuing these other values cooperatively-in which case they might be legitimate aims (at a different level than the values considered in this article) but perhaps merely instrumental and/or not independent), security (which partly involves protecting against major utility losses rather than just maximizing utility) and procedural justice. Discussion of other plausible social values is important to further development of moderate pluralism, but beyond the scope of this article.

8. The canonical bioethics framework of Beauchamp and Childress (2001) is, of course, pluralistic - but it is thin on detail about how to handle cases (analogous to cases of value conflict considered in this article) where their famous four principles conflict. The difficulty in dealing with conflict among their four principles is noted/discussed by Dawson and Garrard (2006).

9. The following discussion draws from Selgelid (2002).

10. I leave to the side, for now, questions about how these things should be measured.
11. In what follows, I assume that the nature of the equality (as characterized) is not captured by the measurement of equality.

12. On an absolute (rather than relative) scale.

13. Improvement of global health could also be achieved via charitable donation. I here assume that redistributive taxation is necessary, however, because charitable donation has thus far proven insufficient.

14. For the sake of simplicity, the discussion that follows focuses on the two-dimensional conflict between utility and liberty (under the assumption that equality is not an issue in the context under consideration). In cases where more than two values conflict, a more complicated (though analogous) threedimensional analysis would be necessary. Though I do not discuss equality in what follows, I do not mean to suggest that equality should not be taken into consideration when analyzing conflict between liberty and utility.

15. Though I refer to DALYs—'Disability Adjusted Life Years'-as a plausible measure of disease burden (partly because the DALY is arguably the best developed and most widely used metric for disease burden), it should be noted that the DALY metric is controversial and that there are other plausible metrics of disease burden. Nothing in the argument that follows turns on reliance on the DALY metric in particular. Discussion of disease burden metric is beyond the scope of this article-but see Selgelid (2008b). In what follows the reader may take 'DALY' to be a proxy for the best metric for disease burden (whatever that turns out to be).

16. I am assuming that equality is not an issue in context under consideration.

17. If there was an actual turning point in the spectrum, however, I admit that there would be some value in knowing where it is. It would, after all, be the ideal place to use as a cutoff point for policy purposes. Failure to achieve an ideal policy solution, on the other hand, is not always crucial (as illustrated by comparison of cases where 9.999999 and 10.000001 DALYs are at stake).

\section{Acknowledgements}

Earlier versions of this paper were presented in the Political Theory and Public Health stream of the Manchester Workshops in Political Theory, 11 September 2008; a Public Health Ethics Workshop held at the Joint Centre for Bioethics, University of Toronto, 11 December 
2008; and in a Center for Applied Philosophy and Public Ethics (CAPPE) seminar, Charles Sturt University, Wagga Wagga, 26 June 2009. I thank participants at these events for their valuable comments. I am especially grateful to Angus Dawson for his role in organizing and inviting me to participate in the first two events-and for providing extensive comments on an earlier draft that led to substantial improvement of the paper (though I may not have addressed all of his concerns to his satisfaction). I thank the Brocher Foundation (www.brocher.ch) in Hermance (Geneva), Switzerland, for hosting me as a visiting researcher during the period this paper was completed in 2009. Work on this paper was also supported by an Australian Research Council (ARC) Discovery Project Grant (with Christian Enemark) on 'Infectious Diseases, Security and Ethics'.

\section{References}

Beauchamp, T. L. and Childress, J. F. (2001). Principles of Biomedical Ethics, 5th edn. New York: Oxford University Press.

Brock, D. (1993). Quality of Life Measures in Health Care and Medical Ethics. In Brock, D., Life and Death. New York: Cambridge University Press.

Buchanan, A., Brock, D. W., Daniels, N. and Wikler, D. (2001). From Chance to Choice. New York: Cambridge University Press.

Daniels, N. (1985). Just Health Care. New York: Cambridge University Press.

Daniels, N. (2007). Just Health: Meeting Health Needs Fairly. New York: Cambridge University Press.

Dawson, A. and Garrard, E. (2006). In Defence of Moral Imperialism: Four Equal and Universal Prima Facie Duties. Journal of Medical Ethics, 32, 200-204.

Dworkin, R. (1978). Taking Rights Seriously. Cambridge, MA: Harvard University Press.

Farmer, P. (2001). Infections and Inequalities: The Modern Plagues. Berkeley, CA: University of California Press.

Gostin, L. (2006). Public Health Strategies for Pandemic Influenza: Ethics and the Law. JAMA 295, 1700-1704.
Griffin, J. (1986). Well-Being. New York: Oxford University Press.

Kass, N. E. (2001). An Ethics Framework for Public Health. American Journal of Public Health, 91, 17761782.

Kitcher, P. (1996). The Lives to Come. New York: Simon and Schuster.

Nozick, R. (1974). Anarchy, State, and Utopia. New York: Basic Books.

Rawls, J. (1971). A Theory of Justice. Cambridge, MA: Harvard University Press.

Rawls, J. (1993). Political Liberalism. New York: Columbia University Press.

Selgelid, M. J. (2002). Societal Decision Making and the New Eugenics. Grey Series 30. Bad NeuenahrAhrweiler GmbH, Germany: European Academy (Europaische Akademie) for the Study of Consequences of Scientific and Technological Advance, available from: http://www.ea-aw.de/fileadmin/ downloads/Graue_Reihe/GR_30_Eugenics_042002. pdf [accessed 15 March 2009].

Selgelid, M. J. (2005). Ethics and Infectious Disease. Bioethics, 19, 272-289.

Selgelid, M. J. (2008a). Ethics, Tuberculosis, and Globalization. Public Health Ethics, 1, 10-20.

Selgelid, M. J. (2008b). A Full-Pull Program for the Provision of Pharmaceuticals: Practical Issues. Public Health Ethics, 1, 134-145.

Selgelid, M. J. (2009). Pandethics. Public Health, 123, 255-259.

Sen, A. (1992). Inequality Reexamined. Cambridge, MA: Harvard University Press.

Sen, A. (1999). Development as Freedom. New York: Anchor Books.

Singh, J. A., Upshur, R. and Padayatchi, N. (2007). XDRTB in South Africa: No Time for Denial or Complacency. PLoS Medicine, 4, 0019-0025, available from: www.plosmedicine.org [accessed 12 April 2007].

Upshur, R. (2002) Principles for the Justification of Public Health Intervention. Canadian Journal of Public Health, 93, 101-103. 